Journal of Sustainability Perspectives

journal homepage: https://ejournal2.undip.ac.id/index.php/jsp/

\title{
Methods to Decrease Carbon Emission at the University of Szeged
}

\author{
László Gyarmati, ${ }^{1 *}$ \\ ${ }^{1}$ Management, University of Szeged, Study and Information Centre, Szeged 6722, Hungary \\ *corresponding author: gyarmati.laszlo@tik.u-szeged.hu
}

\section{Article Info}

Received:

15 March 2021

Accepted:

25 May 2021

Published:

1 August 2021

DOI:

Presented in The $6^{\text {th }}$ International (Virtual) Workshop on UI GreenMetric World University Rankings (IWGM 2020)

\begin{abstract}
The implementation of innovations and technologies to decrease carbon emission is one of the main priorities that the University of Szeged is striving to achieve. Although, effective investments cannot be carried out without proper measurement systems in energy management and carbon emission monitoring. Understanding the importance of proper measurement, the University of Szeged has decided to calculate the whole carbon footprint of one of its main buildings, namely, the Study and Information Centre with the help of KÖVET association. The carbon evaluation uses data of 2019 and contains the direct and indirect carbon emission of building management, and of its employees' and visitors'. This calculation will be the basis of further carbon reduction investments, protocols and events held for shaping the visitors' and employees' consciousness. In parallel with the evaluation, the University of Szeged has made some huge steps to decrease carbon emission factors. For instance, a newly installed visitor monitoring system regulates the electricity usage of ventilation in the most used areas of the Study and Information Centre based on the actual number of visitors present in the building. Furthermore, from April 2020, five electric cars substitute the most driven cars of the University in urban areas, rapidly decreasing the direct carbon emission in the city.
\end{abstract}

\section{Keyword:}

Sustainability, University of Szeged, carbon footprint, bilan carbone

\section{Introduction}

The University of Szeged is one of the biggest universities in Hungary with around 22.000 students and 6000 academic and administrative stuff. Meeting the aims of the Third Mission of the Development Strategy of the University of Szeged, the Institution makes every effort each year to be more and more environmental conscious and 'green' [1]. There are many green technologies that the University of Szeged already implemented such as using geothermal energy, installing solar panels, constructing smart building and finding new ways to decrease carbon emission. (More can be read about those technologies in 
Expansion of renewable energy resources and energy conscious behavior at the University of Szeged [2].)

Due to continuous improvement, the University of Szeged is in the high end in the list of green universities according to UI GreenMetric World University Ranking (Table 1.) [3].

Table 1. Achievements of the University of Szeged in GreenMetric

\begin{tabular}{clll}
\hline Year & $\begin{array}{c}\text { Place of the University } \\
\text { of Szeged/number of } \\
\text { Universities taking part } \\
\text { in the ranking }\end{array}$ & $\begin{array}{c}\text { Proportion of European } \\
\text { Universities in the } \\
\text { ranking behind the } \\
\text { University of Szeged }\end{array}$ & $\begin{array}{c}\text { Difference in points } \\
\text { between the University } \\
\text { in the first place and the } \\
\text { University of Szeged }\end{array}$ \\
\hline 2010 & $54 . / 95$ & $44 \%$ & 2972 \\
2011 & $67 . / 178$ & $70 \%$ & 2232 \\
2012 & $52 . / 215$ & $82 \%$ & 1738 \\
2013 & $35 . / 301$ & $88 \%$ & 1192 \\
2014 & $19 . / 360$ & $92 \%$ & 885 \\
2015 & $29 . / 407$ & $90 \%$ & 1038 \\
2016 & $107 . / 516$ & $90 \%$ & 2751 \\
2017 & $88 . / 619$ & $79 \%$ & 1179 \\
2018 & $77 . / 719$ & $85 \%$ & 2075 \\
2019 & $74 . / 780$ & $84 \%$ & 1700 \\
\hline
\end{tabular}

To enhance the decreasing of the carbon emission of the University, two tasks are to be completed: the proper and exact evaluation of carbon emission factors and finding new, affordable technologies to decrease direct and indirect emission.

\section{Carbon Footprint Evaluation}

With The KÖVET association for Sustainable Economies the University of Szeged has decided to calculate the whole carbon footprint of one of its main building, the Study and Information Centre using the Bilan Carbone method developed by the French Environment and Energy Agency (ADEME) for calculating greenhouse gas emission. The Centre has been a combination of a Studying Area, a Teaching Area, a Service Area, a Conference Site and a Meeting Place for its daily 3000-3500 visitors for more than 15 years thus being the ideal place for a reference calculation. The carbon evaluation uses data of 2019 and contains the direct and indirect carbon emission of building management, and of its employees' and visitors'. The considerable sources are the follows:

- Fossil fuels and electricity

- Activities excluding use of energy Future Packing

- Materials, products and services purchased Transporting people

- Materials, products and services purchased for packaging Capital goods

- Transportation of goods

- Transporting people

- Waste produced by the entity

- The manufacture of durable goods used by the entity

- The use stages of the product or service sold or distributed

- End-of-life treatment of products sold or distributed

The method is suitable for monitoring the emission factor of both private and public 
sector because the toolset contains every greenhouse gas emission factor listed in the Kyoto Protocol. The calculation is accepted for monitoring the appropriateness of carbon neutralization programs for ISO 14054 standards, too [4]. To represent the practical use of the method, the French supermarket chain called Leclerc, indicates the carbon-dioxide emission of every purchase on the invoice by this toolset [5].

For the precise calculation, the researchers combine two gathering data methods: online and offline surveys of the visitors of the Centre, and data procession of internal documentation of the building management. The survey was conducted from February to March in 2020, and the 33 questions covered four areas related to carbon emission factors:

- Transportation (within Szeged for daily transportation, and frequency travels from hometown to the City)

- Nutrition (In the Study and Information Centre, and daily habits)

- Waste management (In the Centre during visits, and habits/possibilities at home)

- Environmentally Conscious behavior (opinions about performance of the university, beliefs, recommendations)

1754 people submitted the survey, and the results are being double-checked and processed while this article is being written. In parallel with this survey, the researchers gathered building management related data of the operating process of the building as well, for instance: weight of organic and inorganic waste, electricity and heating gas usage, work related travels, renewable energy production, purchased goods and services, etc.

This calculation will be the basis of further carbon reduction investments, protocols and events held for shaping the visitors' and employees' consciousness.

\section{Carbon Decreasing Methods}

The University of Szeged has already installed numerous technologies as mentioned in the introduction. Furthermore, applying more energy saving and carbon decreasing technologies are encouraged by reallocating returns from previously installed solutions (e.g., solar panels). In this section, we describe the positive financial, and carbon reduction effects of those new investments.

\subsection{Frequency Inverters at the Study and Information Centre}

The Study and Information Centre welcomes 2.000-3.000 visitors on daily bases, and around $17.000 \mathrm{~m}^{2}$ floor are open for the users of the services provided by the Centre. The Centre is equipped by eight ventilation machines responsible for ventilating fresh air for the offices and for the social area of the building. Those technologies have been operating on full capacity for 15 years, causing one of the major portions of electric usage of the building. Those ventilation systems can be altered with frequency inverters, which are able to monitor the real time utilization of areas and are able to regulate and optimize the electricity consumption of those ventilation technics, lowering the electricity consumption dramatically, and the carbon factor of the building as well. The cost, savings/year and rate of return calculations of those technologies are shown in Table 2. 
Table 2. Returns based on nominal capacity

\begin{tabular}{cccccc}
\hline $\begin{array}{c}\text { Machine } \\
\text { No. }\end{array}$ & Area & $\begin{array}{c}\text { Cost } \\
\text { (Dollar) }\end{array}$ & $\begin{array}{c}\text { Savings/year } \\
\text { (Dollar) }\end{array}$ & $\begin{array}{c}\text { Rate of } \\
\text { return } \\
\text { (years) }\end{array}$ & $\begin{array}{c}\mathrm{CO}_{2} \text { emission } \\
\text { reduction } \\
\text { (tons/years) }\end{array}$ \\
\hline L04 & $\begin{array}{c}\text { Reading } \\
\text { rooms }\end{array}$ & 12400 & 12295 & 0,9 & 43,89 \\
L07 & $\begin{array}{c}\text { Conference } \\
\text { room }\end{array}$ & 14390 & 11397 & 1,3 & 33,69 \\
L10 & $\begin{array}{c}\text { Cabinet } \\
\text { Book }\end{array}$ & 7624 & 5550 & 1,4 & 16,64 \\
L11 & 7624 & 5180 & 1,5 & 15,54 \\
L12 & $\begin{array}{c}\text { storage } \\
\text { Offices }\end{array}$ & 7624 & 7171 & 1,1 & 21,51 \\
\hline
\end{tabular}

The first two investments (L04, L07) were conducted in 2019, and the empirical measures confirm the estimated rate of returns and the volume of $\mathrm{CO}_{2}$ reduction. The closure of the building due to the pandemic situation has a significant effect on the rate of returns, but the technology can be used sufficiently after the pandemic deregulations, too.

\subsection{Electric Cars}

The University of Szeged manages 286 properties that are scattered around the city of Szeged. Every faculty has its own campus, but there are some buildings, which are used by more than one faculty. Also, the whole clinical infrastructure of Szeged is integrated into the University. Therefore, there are 33 cars actively used and managed by the University to transport documents, people and supply from one building to another. With the successful cooperation with the Ministry for Innovation and Technology, the University obtained 5 electric cars, with 4 chargers to substitute the most driven, inefficient diesel cars used in urban areas [6].

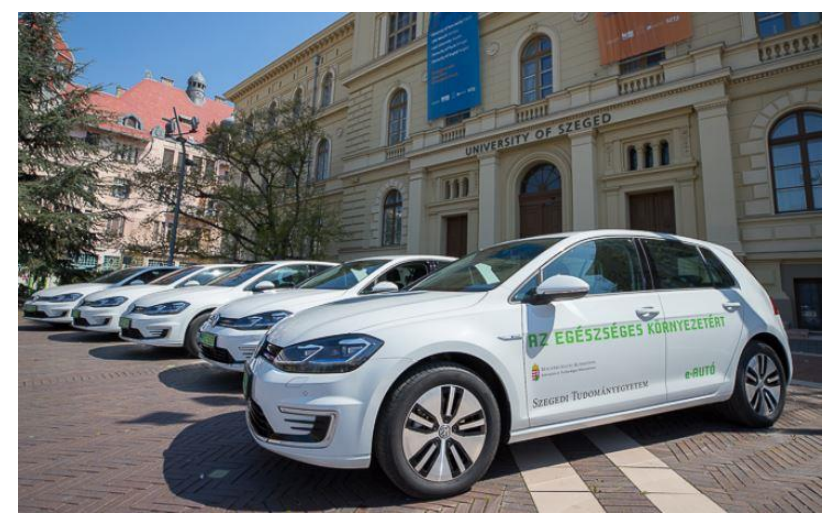

Figure 1. Electric cars in front of Rector's office

With this improvement, the calculated $\mathrm{CO}_{2}$ emission of the University's car fleet is dropped by 16.000 tons/year, which is $15 \%$ reduction of direct emission caused by cars. At the site of the Study and Information Centre, a free of charge electric car charging point was installed in 2017 [7]. Since then, 71 charges/month on average have been completed with the help of the $80 \mathrm{~kW}$ capacity of solar panels installed on the roof of the Centre. 


\section{Summary}

With the latest improvements, the University of Szeged is capable to continue carbondecreasing processes and for that, it is essential to reinvest the funds to energy saving technologies continuously, created by the use of renewable energy-based technologies.

Although technical solutions can be one pillar of decreasing carbon emission, the final impact strongly depends on the energy conscious behavior of the students, employees and visitors of the University, too. Reflecting on that responsibility, the University continuously organizes events for educating people towards a more sustainable lifestyle (e.g.: green office education, technical tours to understand renewable technologies and playful green events for kids). With the COVID-19 pandemic outbreak, most of the universities are forced to move their teaching methods to online platforms and minimalize social contacts at the university areas. This led to a significant drop of energy usage (and due to lack of transportation: carbon emission) of campuses, and at the end of the pandemic situation it will be necessary to consider which online solution should be kept in order to maintain energy efficient solutions on the long run.

\section{References}

1. University of Szeged Institution development plan, Available online at http://www.uszeged.hu/egyetemrol-141002/minosegfejlesztesi/szte-ift-2016-2020-170124, accessed on $18^{\text {th }}$, May (2020)

2. Gyarmati, L., 2018. Expansion of renewable energy resources and energy conscious behavior at the University of Szeged. In: E3S Web of Conferences 48, 03006 IWGM 2018

3. UI GreenMetric, 2010-2019. UI GreenMetric world university ranking. Available online at http://greenmetric.ui.ac.id/, accessed on $12^{\text {th }}$, May, 2020.

4. Pelletier P., Allasker K., Pant R. \& Manfredi S., 2014. The European Commission Organization Environmental Footprint method: comparison with other methods, and rationales for key requirements. The Internal Journal of Life Cycle Assessment, Volume 19, pp. 387-404.

5. Schaefer F., Blanke M., 2014. Opportunities and challenges of carbon footprint, climate or $\mathrm{CO} 2$ labelling for horticultural products. Erwerbs-Obstbau, Volume 56, pp. 73-80.

6. Press release about the acquisition of five cars for the University of Szeged, available online at https://u-szeged.hu/sztehirek/2020-aprilis/elektromosautokat?objectParentFolderld=19396, accessed on 17th, May, 2020

7. Press release about installing electric car charger 2017, available online at https://uszeged.hu/sztehirek/2017-szeptember/elektromos-auto, accessed on 17th, May, 2020 